\title{
Base formal en la polisemia del partitivo mayoría
}

\author{
Formal basis in the polysemy \\ of the partitive mayoría
}

\author{
Javier San Julián Solana \\ Universidad de Oviedo \\ jsanjulian@uniovi.es
}

ORCID ID: https://orcid.org/0000-0001-7866-6142

\begin{abstract}
RESUMEN: El objetivo de este artículo es mostrar que las diversas acepciones del sustantivo mayoría en las que está presente la noción de 'partitividad' llevan asociadas una serie de marcas formales que permiten su discriminación. Por poner el foco en los aspectos morfosintácticos, el análisis aplicado nos lleva a advertir diferencias semánticas que han pasado desapercibidas a los lexicógrafos. Los datos expuestos, que mitigan en parte la falta de atención dedicada a este sustantivo en la tradición gramatical, también pueden resultar provechosos en la enseñanza del español y en el desarrollo de estudios de corte cuantitativo.
\end{abstract}

Palabras clave: mayoría, partitivo, sustantivo cuantificador, sustantivo colectivo, gramática, lexicografía, enseñanza del español.

ABSTRACT: The aim of this paper is to show that the various meanings of the noun mayoría in which the notion of 'partition' is present are associated with a series of formal marks that allow their discrimination. Focusing on morphosyntactic aspects, our analysis allows us notice semantic differences that have gone unnoticed by lexicographers. The data provided, which partially mitigate the lack of attention dedicated to this noun in the grammatical literature, may also be both useful in teaching Spanish and preparing on quantitative studies.

Keywords: majority, partitive, quantifier noun/quantifying noun, collective noun, grammar, lexicography, teaching of Spanish. 


\section{INTRODUCCIÓN}

\subsection{Mayoría en la tradición gramatical}

Por sorprendente que resulte, dada su amplitud de uso, el sustantivo mayoría apenas ha recibido atención en la tradición gramatical hispánica. En muchos de los más relevantes tratados, ni siquiera se menciona (v. g., Salvá, 1830; Be1lo, 1981 [1847]; Seco, 1968 [1930]; RAE, 1931; Alonso y Henríquez Ureña, 1969 [1938] y 1969 [1939]; Seco, 1989 [1972]; RAE, 1973; Alcina Franch y Blecua, 1998 [1975]; Alarcos, 1994).

Como en otros aspectos relacionados con los cuantificadores del español, la gramática de Fernández Ramírez (1987 [1951]: 376-377) supone una excepción, al dedicarle unas pocas líneas a la mayoría. Este autor incluye dicha unidad y la mayor parte entre los "pronombres indefinidos", al tiempo que destaca su categoría sustantiva, su vinculación con el artículo, su capacidad para funcionar como "indefinidos cuantitativos anafóricos en función de término primario", su número singular y la preferencia del verbo a intervenir en plural cuando concierta con ellos.

Más recientemente, se encuentran alusiones varias, aunque de escaso calado, en la gramática colectiva dirigida por Bosque y Demonte (1999). El propio Bosque (1999: 41) lo menciona para incluirlo entre los "nombres cuantificativos de grupo" y apartarlo, en consecuencia, de la clase de los colectivos. En otro capítulo de la misma obra, Martínez (1999: 2778) insiste, a propósito del fenómeno de la concordancia, en extraerlo del inventario de los colectivos - que tienen muy limitada su capacidad para suscitar la llamada concordancia "ad sensum" - y en incluirlo en el paradigma de los cuantificativos — que no presentan tales restricciones-. Más allá de esta "reclasificación", no aporta datos sobre sus múltiples manifestaciones, a pesar de que, como veremos, es algo que tiene importantes implicaciones sobre la concordancia. En fin, tampoco Brucart (1999: 2858), en el capítulo siguiente, aporta mucha más información a propósito de este cuantificador: se limita a señalar que permite la elipsis nominal, y recurre a él en su argumentación en contra de la postura tradicional que distingue entre adjetivos determinativos y pronombres - lo cual conlleva una duplicación categorial - y a favor de la de los "sintagmas nominales con núcleo elíptico".

En la NGLE se reconoce su condición de fraccionario, aunque no guarda correspondencia con ningún elemento de la serie de los números naturales (ibíd.: 1536). Sin embargo, tampoco es objeto de un estudio detallado. De lo que sí se informa en diversos pasajes de la obra (ibíd.: 1059-1060, 1451-1452, 1537) es de la actual tendencia — ya censurada en el $D P D$ (s. v. el, § 8)- a omitir el artículo en los complementos de las construcciones partitivas con la mayoría y la mayor parte, sin que ello suponga "la conversión de la construcción partitiva en pseudopartitiva" (NGLE: 1060). 
En suma, los tratados gramaticales al uso no rastrean la existencia de posibles marcas formales que permitan diferenciar los diversos valores de contenido que esta unidad sustantiva llega a adoptar, y de los que nada suele decirse.

Brucart (1997) y De Miguel (2003) sí hablan de la posibilidad de que mayoría no se use como partitivo, sino como unidad "referencial", en cuyo caso no suscita el fenómeno de la silepsis; ahora bien, nada más dicen al respecto. También Demonte y Pérez-Jiménez (2015: 62) aluden tangencialmente a que mayoría pude designar un "objeto", concretamente cuando tiene "el sentido de "mayoría parlamentaria"”. En fin, en Pérez-Jiménez y Demonte (2017) se advierte de que para algunos autores el número del verbo, cuando el sujeto es una construcción partitiva, está determinado por el carácter ora cuantitativo, ora referencial de la cabeza — esta es la postura de Rodrigues (2011) para el portugués majoria -

Aunque insuficiente, la mayor aproximación en este sentido es la que lleva a cabo Fält (1972: 132-133) en su monografía acerca de la concordancia en español moderno, en la que mayoría queda clasificado como un colectivo "no organizado" y en la que se afirma que, cuando interviene en la función de sujeto y lleva un complemento en plural, el verbo suele concordar también en dicho número. Algunas de las apreciaciones de este autor revelan - en términos muy imprecisos, eso sí- la intuición de que deben distinguirse varias acepciones, dada la repercusión que esto tiene en el plano gramatical, y particularmente en la concordancia sujeto-verbo. Así, justifica el singular verbal en un ejemplo ${ }^{1}$ diciendo que en tal caso "se insiste en la mayoría como tal, en el hecho de que hubiese tantas cruces azules; no se trata simplemente de la mayor parte de" (ibíd.: 132). Y a continuación sostiene: "Cuando mayoría se emplea en un sentido 'técnico' (mayoría política, sondeos de opinión) [...], parece ser que el singular es relativamente más frecuente que el plural" (ibíd.: 133). También barrunta que el complemento en el que el sustantivo no lleva artículo, demostrativo o posesivo "admite más fácilmente la concordancia formal que el tipo con artículo" (ibíd: 132), con el que predomina la concordancia ad sensum. Finalmente, llama la atención sobre el hecho de que, si el complemento no se explicita, "pueden emplearse las dos formas" (ibíd.: 133) en el verbo, la de singular o la de plural.

\subsection{Objetivos y metodología}

En este artículo nos proponemos ahondar en el estudio de mayoría con el fin de paliar, al menos parcialmente, la desatención de la que ha sido objeto en la bibliografía especializada. En particular, nuestro objetivo pasa por dirimir si

\footnotetext{
${ }^{1}$ El ejemplo en cuestión, tomado de una obra de Martín Gaite, es el siguiente: "Pero la asombrosa mayoría de cruces azules me dejó muy perplejo" (Fält, 1972: 132).
} 
las distintas acepciones en las que está presente el rasgo de 'partitividad' son solidarias con rasgos formales o si, por el contrario, ha de verse en ellas meros sentidos originados pragmáticamente en función de las concretas circunstancias en que se lleva a cabo el acto comunicativo.

Para ello, nos servimos de los principios teórico-metodológicos de la escuela funcionalista desarrollada a partir de la obra de Emilio Alarcos Llorach (cfr. San Julián Solana, 2014: 18-23).

\section{LA POLISEMIA DE MAYORÍA}

El estudio del sustantivo mayoría - obtenido por derivación heterogénea (Alarcos, 1969 [1951]: § 64) a partir del adjetivo mayor, comparativo sintético de superioridad de grande - nos enfrenta a un sintagma ${ }^{2}$ polisémico cuyas acepciones oscilan entre lo cuantificativo y lo puramente designativo ${ }^{3}$. Aunque las distinciones lexicográficas pueden no ser exhaustivas —aquí mismo se ofrecerá una muestra de ello (v. infra) - o, por el contrario, reflejar valores que siguen siendo subsidiarios del contexto (i. e., pragmáticos) a pesar de contar con cierto grado de convencionalización, lo cierto es que los principales diccionarios de lengua española (DLE, DUE, DEA: s. v. mayoría) dejan constancia de la polisemia de este sustantivo. Si se atiende a la presencia o ausencia del rasgo de 'partitividad', las acepciones en ellos reconocidas pueden dividirse en dos grupos:

I. acepciones en las que está presente el rasgo de 'partitividad':

a) 'la mayor parte de un conjunto de personas o cosas' (DLE: acep. 5; DUE: acep. 2; DEA: acep. 1);

b) 'parte mayor de las personas que componen una nación, ciudad o cuerpo' (DLE: acep. 4);

c) 'mayor número de votos conformes en una votación' (DLE: acep. 3; $D E A$ : acep. 1c);

\footnotetext{
${ }^{2}$ Nótese que, en el paradigma teórico al que nos adscribimos, el término sintagma se emplea para aludir al 'mínimo signo susceptible — sin contar los casos de mención - de constituir un enunciado al recibir una curva entonativa', y no de la manera en que lo hacen Saussure (1986 [1916]: 197) o Martinet (1974 [1960]: 142-143).

${ }^{3}$ Entendemos que la designación es la relación que se establece entre algunos signos lingüísticos y una clase de realidades que satisfacen los rasgos semánticos esenciales de aquellos (solo al ir debidamente "actualizados", algunos de tales signos pasan a denotar ejemplares particulares de la clase designada). De todos modos, los rasgos pertinentes de contenido de las unidades determinativas no se orientan tanto a definir una clase de entidades como a especificar la aplicación referencial de otros signos. Una de las operaciones de determinación en el ámbito (ad)nominal es, precisamente, la cuantificación (cfr. San Julián Solana, 2016a: § 3.3.1 y 3.3.2; íd., 2019: § 2).
} 
II. acepciones que carecen del rasgo de 'partitividad':

a) 'cualidad de mayor' (DLE: acep. 1; DUE: acep. 1);

$b)$ 'condición de quien ha cumplido la edad establecida por la ley para que pueda disponer de sí y de sus bienes' [mayoría de edad] (DLE: acep. 2; DUE: acep. 3; DEA: acep. 2);

c) 'condición de la persona que ha llegado al estado adulto' (DEA: acep. 2b);

d) 'oficina del mayor general' (DLE: acep. 6; DEA: acep. 3);

e) 'oficina del sargento mayor' (DLE: acep. 7; DEA: acep. 3).

En este trabajo nos centraremos en las del primer grupo, que conllevan la idea de 'segregación de la mayor de las partes que se distinguen en un todo'. Este aspecto en común no hace sino dificultar la distinción entre los valores estrictamente cuantitativos y aquellos más orientados a la designación.

A este respecto, adelantamos que el análisis gramatical que hemos efectuado pone de manifiesto la heterogeneidad subyacente a la primera de las acepciones previamente mencionadas ('parte mayor de un conjunto de personas o cosas'). Por un lado, ha de considerarse mayoría como sustantivo cuantificador partitivo proporcional referido a la 'mayor parte de una totalidad presentada como homogénea en cuanto a la (sub)clase designativa de sus componentes’ (§ 3 ):

(1) La mayoría de los alumnos suspendieron el examen; Él solito se ha zampado la mayoría de los caramelos.

Pero, por otro lado, mayoría también puede designar la 'parte mayor de una totalidad heterogénea en lo tocante a la (sub)clase de sus elementos integrantes', en cuyo caso se comporta como un sustantivo colectivo ${ }^{4}(\S 4)$ :

(2) En mi clase hay una mayoría de alumnos extranjeros; Parece que los corruptos son mayoría entre nuestros políticos.

Claro está, si se atiende solo a la sustancia de contenido, resulta muy difícil apercibirse de esta diferencia (no es casual que haya pasado inadvertida incluso a la mirada experta de los lexicógrafos); es al volcar la atención en el nivel morfosintáctico cuando termina revelándose.

\footnotetext{
${ }^{4}$ Concebimos los sustantivos cuantificadores como sintagmas de categoría sustantiva y significación o sentido (predominantemente) determinativo que, al ir cuantificados o incorporar un "determinante", dan lugar a secuencias cuantificativas destinadas a expresar la cantidad en que se da o concibe lo significado por otro sustantivo; si este último (el cuantificado) no adquiere realización material en el plano de expresión, ha de recuperarse forzosamente en el plano de contenido (cfr. San Julián Solana, 2016a y 2016b). No son cuantificadores intrínsecos o propios los integrantes de la variopinta clase de los sustantivos colectivos, a los que nos referiremos posteriormente $(\S 4$, n. 23$)$.
} 


\section{MAYORÍA, CUANTIFICADOR PARTITIVO-PROPORCIONAL}

\subsection{Significación y su repercusión combinatoria}

En cuanto puro cuantificador, este sustantivo se refiere, en principio, a la 'mayor parte (con relación a la suma de todas las demás) de un conjunto'5. Y es que, fundamentalmente, son sustantivos en plural o singulares colectivos los encargados de denotar la totalidad fraccionada. Esto convierte al sintagma mayoría en una unidad semánticamente más específica que la expresión analítica (la) mayor parte, que no se ve sujeta a restricciones combinatorias de esa índole, por cuanto no ofrece resistencia a la hora de aplicarse a sustantivos individuales en singular.

De todos modos, en el actual estado de la lengua resulta un tanto aventurado elevar la pluralidad (morfológica o léxica) del sustantivo complementario al rango de condición necesaria para la gramaticalidad del enunciado, ya que, aunque mucho menos frecuentes, y por más que sean censuradas en la norma académica (DPD: s. v. mayoría), no resulta difícil recabar muestras reales en las que el sustantivo encargado de expresar el todo es un individual en singular, casi siempre medible:

(3) a. Según la propia Conferencia Episcopal, la mayoría del dinero recibido del Estado se destina a gastos de personal de las diócesis y a la seguridad social del clero diocesano [El País, 1/8/1984, apud CREA];

b. En la actualidad la mayoría del gas proviene de la Costa Atlántica y se transporta por gasoducto hasta el interior [Revista Semana (Colombia), 9-15/10/2000, apud CREA];

c. Muriel pasa la mayoría del tiempo encerrada en su cuarto oyendo al grupo Abba y sueña con casarse [El Tiempo, 4/9/1996, apud CREA];

d. Ello se tradujo en que los delanteros azulgrana pisaron el área francesa en escasísimas ocasiones y que la mayoría del peligro que crearon llegó en lanzamientos lejanos [La Vanguardia, 2/3/1995, apud CREA];

aunque muy esporádicamente la unidad cuantificada es un contable en singular:

(4) a. Tiene la ventaja, además, de que el carril-bus va aparte en la mayoría del trayecto [El País, 2/11/1980, apud CREA];

b. Para quienes viajamos en primera en la nave espacial que es la Tierra es difícil hacernos idea de los niveles de miseria social y de destrucción ecológica-ambiental que hoy día están asolando a la inmensa mayoría del planeta [El Norte de Castilla, 14/2/2001, apud CREA].

\footnotetext{
5 Tal y como apunta López Palma (2011: 48, n. 1), la lectura de base numérica ('al menos la mitad más uno') que ocasionalmente se plasma en algunas definiciones de mayoría no se logra composicionalmente a partir de los signos constituyentes de este sustantivo (mayor + -ía), "sino que es una adaptación de un concepto numérico $(>1 / 2)$ a un concepto aproximado del lenguaje ordinario".
} 
Con todo, el uso que se hace de los sustantivos trayecto y planeta en los ejemplos de (4) los acerca a los medibles, ya que las realidades que denotan son consideradas no tanto en su entidad individual - esto es, singularizadas y opuestas a las demás de su especie- como en su extensión interna ${ }^{6}$.

Por lo tanto, a pesar de que en verdad el cuantificador mayoría tiende de manera muy acusada a regir el rasgo 'plural' en el sustantivo al que se aplica semánticamente (este puede contenerlo en su lexema o incorporarlo por vía morfemática), también es cierto que su empleo referido a individuales de número singular no resulta ajeno a los usos generales. Es algo que no se refleja en las respectivas definiciones del DLE (s. v. mayoría, acep. 5) y del DUE (s. v. mayoría, acep. 2) ni en el trabajo de López Palma (2011: 48-49). Más llamativo es que tampoco contemplen esta posibilidad ni Demonte y Pérez-Jiménez (2015: 71) ni Pérez-Jiménez y Demonte (2017: 375), ya que los corpus que estas autoras emplean en ambos estudios - entre los que se encuentra el $C R E A$ - no están exentos de este tipo de muestras (v. ejemplos [3] y [4]). Por el contrario, el $D E A$ (s. v. mayoría, acep. 1b) sí que advierte que a veces la totalidad fraccionada es "algo único o no numerable", usos estos que califica de semicultos; para ilustrarlo, aporta el siguiente ejemplo extraído de la novela Trampa, de Ángel María de Lera: "Estoy sola la mayoría del tiempo".

Probablemente, estas muestras minoritarias y tachadas de incorrectas constituyan el testimonio de que mayoría ha iniciado un proceso de cambio semántico orientado a su equiparación sustancial con la secuencia cuantificadora (la) mayor parte. Y es que, en el español de hoy, el cuantificativo mayoría puede quedar en todos los casos reemplazado por mayor parte, sin que ello dé lugar a alteraciones en la aplicación referencial (5), mientras que dicha operación no siempre resulta posible en la dirección inversa (6):

(5) a. Han robado la mayoría de los cuadros $\equiv$ Han robado la mayor parte de los cuadros;

b. La mayoría del público salió feliz $\equiv$ La mayor parte del público salió feliz;

(6) a. Se bebieron la mayor parte del vino / ?Se bebieron la mayoría del vino; b. Tiene azul la mayor parte del pie / ??Tiene azul la mayoría del pie.

En el supuesto de que esté teniendo realmente lugar, este fenómeno supondría la extensión del significado de mayoría a expensas de la paulatina pérdida de un rasgo intensional: el de 'pluralidad'.

\footnotetext{
${ }^{6}$ Tampoco debe pasarse por alto que algunos sustantivos individuales contables en singular, al combinarse con adjetivos relacionales —en lo que supone un proceso francamente próximo al de la composición, si no plenamente integrado en él-, pasan a comportarse como colectivos (opinión / opinión pública; mundo / mundo estudiantil, etc.) y se hacen perfectamente compatibles con el cuantificador que ahora nos ocupa: “[...] ha creado indignación [...] en la inmensa mayoría de la opinión pública" (El País, 9/1/1997, apud CREA).
} 


\subsection{Relación con los morfemas de número y artículo}

En cuanto sintagma cuantificador, y en los usos generales, mayoría no adopta nunca el morfema de 'plural', ni siquiera cuando alude a varias totalidades, como se aprecia en el siguiente ejemplo:

(7) \{La mayoría / *Las mayorías\} de los perros y de los gatos tienen pulgas.

Esto no ha de resultar extraño, si se tiene presente que se refiere a una fracción necesariamente única, dada una totalidad determinada.

No obstante, asociados a áreas de Hispanoamérica, se han encontrado ejemplos en los que, sin perder sus plenas propiedades cuantitativas, este sustantivo aparece pluralizado, flexión esta que puede ser también reproducida por el artículo (8) o no (9). Se establece, así, una particular concordancia entre mayoría y el sustantivo complementario - que, en la variedad de (9), deviene en una discordancia entre el cuantificador y el artículo que en él se integra como signo morfológico - de la que no da cuenta Kany (1969 [1963]) en su monografía sobre sintaxis hispanoamericana:

(8) a. Hay un inmenso vacío de infraestructura [...] para las mayorías de los hogares pobres urbanos o rurales [Proceso (México), 24/11/1996, apud CREA];

b. [...] en las mayorías de los países del mundo se emplea [Mario Crespo (Argentina): Cultivo de plantas aromáticas para condimento, Buenos Aires, Albatros, 1986, p. 199, apud CREA];

c. Colombia se ha quedado atrás de las mayorías de los países de América Latina [Polo Democrático Alternativo (Colombia), 9/6/2006, <http:// www.polodemocratico.net/ article.php3?id_article $=1300>$ ];

(9) a. Cabe la pregunta, ¿la actitud de sumisión por parte de la mayorías de los judíos y los otros pueblos, no ayudó a los nazis a considerarse imbatibles? [El Cronista (Argentina), 14/7/1992, apud CREA];

b. La mayorías de los correntinos asistimos impasibles a eventos que nos van a perjudicar [Defensa del Acuífero Guaraní (Argentina): "La mentira y el derecho a contaminar", <http://defendiendo_el_ibera.zoomblog.com/

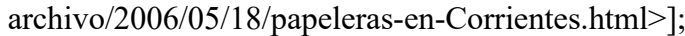

c. Los virus afectan generalmente todo el árbol respiratorio, pero sus manifestaciones clínicas están originadas en la mayorías de los casos sólo en las vías aéreas superiores [Dr. Rodrigo Moreno B. (Chile): "Apunte-25", $<$ http://escuela.med.puc.cl/paginas/cursos/servicio/meb203b/Programa ClasesEnfermeria/Apunte25.doc $>$ ].

En cualquier caso, se trata a todas luces de un fenómeno minoritario y sectorial, ajeno a los usos generales. Esto no obsta para que sea merecedor de atención desde una perspectiva dialectológica (y un enfoque cuantitativo), ya que, si bien no es descartable que nos hallemos ante meros errores de producción, no deja de ser llamativo que todas las muestras encontradas en las que se 
registra esta "atracción" o "contagio" del plural del sustantivo complementario hacia mayoría se circunscriban al español americano.

Por otra parte, en su faceta de cuantificador partitivo proporcional, el sustantivo mayoría recibe básicamente la determinación del artículo. Cabe hablar, nuevamente, de una consecuencia directa de su significado léxico (determinativo), que, como ya indicamos, alude a una parte única respecto de una totalidad concreta. En los ejemplos que siguen puede apreciarse que los demostrativos y los posesivos antepuestos no tienen cabida, ya que presuponen la existencia de otras fracciones de iguales características, lo cual no sucede con el artículo ${ }^{7}$ :

(10) a. Tenía la mayoría de los pantalones rotos;

b. *Tenía esta mayoría de los pantalones rotos;

c. *Tenía mi mayoría de los pantalones rotos.

Por similares razones, cabría esperar su incompatibilidad con un(o)/a/os/as. Pero lo cierto es que, aunque muy minoritarias, hemos hallado muestras en las que mayoría recibe la determinación de una sin que aparentemente se vea privado de su capacidad para nuclear construcciones partitivas (§ 3.3):

(11) a. Una mayoría de los propietarios del teatro está a favor de cederlo a cambio de privilegios [El Mundo, 5/3/1994, apud CREA];

b. Después de todo, una mayoría de los votantes se ha inclinado, desde el 89 en adelante, por la estabilidad de las instituciones y por una muy moderada tendencia al cambio [Hoy (Chile), 26/5-1/6/1997, apud CREA];

c. Una mayoría de los diputados del "subgrupo" parlamentario del PDP pertenecen a los órganos ejecutivos del partido $[A B C, 25 / 1 / 1985$, apud CREA].

El carácter extremadamente residual de una como determinante de mayoría en su faceta de núcleo de construcciones partitivas queda corroborado por los datos numéricos que ofrecen Demonte y Pérez-Jiménez (2015: 32), quienes se ocupan de los casos en los que el grupo partitivo desempeña la función de sujeto léxico. Pues bien, cuando el verbo aparece en singular, las muestras con una se limitan a 6 , frente a las 313 con determinante definido; y el desfase se hace aún más notorio cuando el verbo se presenta en plural: únicamente 3 ejemplos con una frente a los 1263 con determinante definido.

\footnotetext{
${ }^{7}$ En efecto, los demostrativos conllevan la presuposición de existencialidad de algún otro ente de lo referido por el sustantivo al que caracterizan. No idéntica, pero muy similar, es la situación que a este respecto ofrecen los posesivos: si bien estos últimos no conllevan tal presuposición en relación con el poseedor que señalan, sí presuponen la existencia de más poseedores, lo cual tiene también un efecto multiplicador. Si el artículo no conlleva ninguna presuposición de este tipo, es porque únicamente marca como identificable lo referido por el sustantivo, a diferencia de lo que sucede con los demostrativos y los posesivos, que contribuyen a tal identificación ubicándolo en unas coordenadas espacio-temporales o en relación con alguna persona gramatical. Esta información adicional (mayor grado de identificación) resulta totalmente innecesaria cuando el referente es único.
} 
A la vista de estos datos, no ha de extrañar que ni siquiera suela reconocerse la posibilidad que estamos comentando. Bosque (1980: 54), por ejemplo, sostiene que "decimos Votó la mayoría y no Votó una mayoría", mientras que López Palma (2011: 50) declara que "mayoría es únicamente compatible con el artículo definido". Esta última autora ha abordado la cuestión del vínculo entre mayoría y el artículo, para concluir, al igual que nosotros, que dicho "determinante" está impuesto por la semántica de este cuantificador proporcional, en lo que supone un claro contraste con minoría (San Julián Solana, 2006: § 5.3.3.3 y 2016a: $§ 6.3 .2 .4)^{8}$; ahora bien, no se detiene, como aquí hacemos, en el análisis de los distintos valores de contenido de base partitiva - y las marcas formales a ellos asociadas - con que puede contar mayoría.

Este particular fenómeno podría explicarse, al menos a veces, por influjo de los casos en los que mayoría ya cuenta con cierta entidad designativa y, aun con todo, toma complementos que, sin ser estrictamente partitivos, ofrecen algunas similitudes con ellos ( $\$ 4$ y 5). Desde esta óptica, cabría concebir las secuencias destacadas tipográficamente en (11) como el resultado de un cruce de estructuras. De hecho, como veremos más adelante ( $\$ 3.4)$, su combinatoria con adjetivos es mucho menos restrictiva que cuando incorpora el artículo, y se asemeja a la que exhibe en las ocasiones en las que de manera incuestionable gana entidad designativa ( $§ 4.2)$.

Pero, además, la determinación de una abre las puertas a la posibilidad -igualmente presente en la faceta de colectivo que puede tener mayoría (§ 4.4) - de su uso en un sentido relativo, i. e., para aludir a la parte de mayor tamaño en relación con cada una de las demás de la totalidad, pero no respecto del conjunto que estas conforman (valor absoluto):

(12) Telefónica, que todavía conserva una mayoría de las acciones de la cadena, ha iniciado un proceso de desinversión total en Antena 3 TV [...]. Telefónica tiene previsto repartir hasta un $30 \%$ del 34,1 que aún conserva en Antena 3 entre los accionistas de la operadora como dividendo extraordinario [La Razón, 17/6/2003, apud CREA].

\footnotetext{
${ }^{8}$ También polisémico, el sustantivo minoría puede actuar como cuantificador partitivo proporcional, pero entonces no se asocia léxicamente a un referente único, dada una totalidad determinada. Mientras que en su faceta (prototípica) de puro cuantificador mayoría denota una parte y evoca implícitamente la complementaria (§3.3), minoría es compatible con la división de la unidad en más de dos partes, de suerte que el único requisito que ha de satisfacer la fracción diferenciada es el de no ser la más grande en relación con el conjunto de todas las demás. La peculiaridad de definirse negativamente respecto de mayoría queda plasmada de manera ejemplar en la acepción primera del DUE [s. v. minoría]: "Dentro de una colectividad, cada grupo que no constituye mayoría". Así pues, debido a que en una totalidad es viable (y usual) que haya más de una parte con la propiedad de no ser la mayoritaria, una deja de resultar excepcional para convertirse en el "determinante" más frecuente, pudiendo incluso entrar en correlación con otra. Fuera de estas correlaciones, minoría suele adquirir el sentido de 'pequeño número en relación con el total', es decir, 'pequeña proporción'.
} 
En el ejemplo anterior se ve que la expresión una mayoría, aplicada a las acciones de Antena $3 \mathrm{TV}$, no resulta incongruente con el dato de que esas acciones suponen el $34,1 \%$ del total. Ahora bien, no podría sostenerse lo mismo si se hubiera optado por la secuencia cuantificativa la mayoría, que fuerza la lectura partitivo-proporcional absoluta (> $50 \%)$.

Pragmáticamente, sobre todo con apoyo contextual en la correlación una... otra..., el sustantivo mayoría es susceptible de adquirir el sentido de 'conjunto numeroso en relación con el total', en función del cual ya no alude a una parte necesariamente única:

(13) Es el sentir de una mayoría de los tandilenses. Hay otra mayoría de los tandilenses que no se siente interpretada o contenida [El Eco (Argentina), 10/8/2015].

La determinación de una —e incluso la todavía más excepcional del distri-

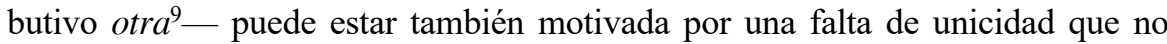
se debe a la pérdida del valor proporcional absoluto, sino que responde a dos actos de segregación distintos aplicados sobre la misma totalidad, y que resultan en fracciones de diferente tamaño, si bien todas ellas cumplen con la condición de ser la mayor respecto del conjunto de todas las demás:

(14) [...] el 54\% [de los ciudadanos españoles] sólo admitirían la vía del diálogo con la banda terrorista en el caso de que ésta entregara las armas. [...] Otra mayoría de los españoles consultados, incluso más sólida (el 56\%), rechazan de forma radical la posible legalización de Batasuna antes de las elecciones [La Voz de Galicia, 21/1/2007, apud CORPES XXI].

Lo limitado del espacio y lo marginal del fenómeno nos impiden profundizar en este asunto, que, sin duda, merece una mayor atención.

\subsection{Estructura del grupo nominal}

Tal y como vimos, los destinatarios de la significación cuantitativa de mayoría son unidades categorialmente sustantivas $\mathrm{y}$, muy preferiblemente, capacitadas para denotar una pluralidad de entes. Dada esta igualdad categorial entre cuantificador y "cuantificado", cuando ambos se integran en el mismo grupo nominal se hace preciso el concurso de la transposición (Martínez, 1994: cap. I), en este caso, de la mano de la preposición de. Entonces, se recurre a una construcción partitiva (Brucart, 1997; Gutiérrez Rodríguez, 2008; Martínez, 2013; Tucci, 2016; San Julián Solana 2018b) en la que el cuantificador (funtivo constante de la relación de dependencia, i. e., núcleo sintáctico) representa la parte segregada, mientras que el sustantivo del complemento introducido por preposi- 
ción (que habrá de portar o incorporar el valor de 'identificabilidad' característico, pero no exclusivo, del artículo) denota la totalidad de la que se desgaja la parte. Dicha totalidad, dentro de los márgenes del grupo sintagmático nominal, queda lingüísticamente presentada como homogénea en lo que a la clase de sus componentes se refiere. Así, el complemento partitivo de (15a) denota un conjunto formado por individuos de una única clase: la de los "alumnos malagueños"; análogamente, todos los integrantes de la totalidad referida por el segundo funtivo del grupo nominal destacado en (15b) pertenecen a la clase de los "obispos":

(15) a. La mayoría de los alumnos malagueños han optado por no ir hoy a clase [La Opinión de Málaga, 21/10/2014];

b. La mayoría de los obispos, a favor de una apertura hacia los divorciados y los homosexuales [El Mundo, 18/10/2014].

A propósito, en su faceta rigurosamente cuantitativa - como potencial núcleo sintáctico de construcciones partitivas canónicas, y al margen de los casos marginales en los que va determinado por una (\$3.2) —, mayoría recibe una lectura absoluta en función de la cual refiere una parte única, al tiempo que evoca la que completa la totalidad. Poco importa que esta otra fracción (la implícitamente aludida) sea susceptible de recibir un reanálisis en múltiples subpartes: en un primer nivel, hay una división del conjunto en dos partes, a saber, la mayor y la restante, necesariamente más pequeña. Es algo que puede comprobarse en (16), donde la fracción minoritaria implícitamente referida (la conformada por los asociados que no votaron a favor) es susceptible de integrar a distintos subgrupos (el de los que votaron en contra, el de los que votaron en blanco, el de los que votaron nulo, el de los que no votaron):

(16) La mayoría de los asociados votó a favor de la propuesta ['el resto de los asociados no votó a favor'].

En otro orden de cosas, si el sustantivo al que este cuantificador se aplica semánticamente se estima recuperable del contexto previo o se da por consabido en la situación del acto comunicativo, no tiene por qué explicitarse bajo la forma de complemento partitivo, sin que ello suponga perjuicio alguno para la relación partitiva, dada la condición de partitivo léxico de mayoría. De hecho, para que resulte posible la asignación de referentes extralingüísticos y, en suma, el enunciado adquiera sentido pleno, el sustantivo que expresa la totalidad ha de recuperarse en el plano de contenido ${ }^{10}$ :

${ }^{9}$ En el CREA no se ha encontrado ninguna muestra en la que mayoría vaya precedido de otra al tiempo que interviene como núcleo de un complemento partitivo, mientras que en el CORPES XXI solo hemos hallado la reproducida en (14).

${ }^{10}$ La idea de que el sustantivo complementario sí forma parte del plano de contenido — de resultas de lo cual ha de ser catalizado (Hjelmslev, 1943: cap. XIX) en el análisis gramatical— enlaza con 
(17) El funcionario precisó que hace dos semanas los casos sospechosos de dengue aumentaron a 89, y la semana pasada disminuyeron a 79. La mayoría [de los casos sospechosos de dengue] fueron reportados en Arecibo, Bayamón y San Juan [El Nuevo Día (Puerto Rico), 14/11/2000, apud CREA].

El registro coloquial nos ofrece, no obstante, una excepción a lo que acabamos de afirmar. Nos referimos a los casos —olvidados por la tradición gramatical- en los que mayoría se emplea con un sentido genérico, cuasi universal, por el que se vuelve equivalente, en términos de sustancia semántica, al neutro todo afectado por la matización aproximativa (por defecto) de casi:

(18) Desde que llegamos a Madrid, la mayoría han sido problemas (三 Desde que llegamos a Madrid, casi todo han sido problemas).

En ejemplos como el anterior, la mayoría carece de la orientación fórica que exhibe en los enunciados de (16) — catafórica - y (17) — anafórica- Al contrario, el todo evocado por mayoría en (18) no es ya una pluralidad definida de objetos de una clase determinada susceptible de ser denotada por un sintagma o grupo sustantivo, sino la práctica totalidad de las circunstancias y acontecimientos que rodean, envuelven o sirven de marco al predicado, y que se convierten ahora en su tema (i.e., la entidad extralingüística sobre la que se predica [Fernández Lorences, 2010: 353]). Esta es la razón por la que resulta harto complicada - si no imposible - la incorporación de un complemento partitivo. Aunque se recurra a un sustantivo de significación genérica (esto es, de mínima comprensión y máxima extensión), como es el caso de $\cos a / s$, el resultado es del todo ajeno a los usos vigentes:

(19) Desde que llegamos a Madrid, la mayoría de las cosas han sido problemas.

En realidad, en (18) no hay ningún sustantivo (ni explícito ni implícito) que denote la totalidad fraccionada, que queda evocada de manera inconceptual. A fin de cuentas, mayoría no es ahí, rigurosamente hablando, un cuantificador ${ }^{11}$.

Por más que siempre incorpore el artículo, mayoría tampoco funciona como unidad cuantificadora en los siguientes ejemplos, en los que se observa que, en

\footnotetext{
la propuesta de Cardinaletti y Giusti (2006: 66-67) para el italiano, posteriormente asumida para el español por Pérez-Jiménez y Demonte (2017: 366-367). Estas autoras, que se inscriben en el paradigma teórico generativista, estiman que el complemento, sin estar fonológicamente expresado, sí se halla presente en el nivel sintáctico como una categoría nula recuperable anafóricamente.

${ }^{11}$ Dada la preocupación del generativismo por la representación formal $-\mathrm{y}$ a pesar de las observaciones efectuadas en el párrafo que antecede a (19) - , un análisis con este enfoque seguramente encontrará más coherente postular la presencia de un nombre genérico nulo a modo de complemento.
} 
una de sus acepciones — la recogida en cuarto lugar en el $D L E$ - ha sufrido un proceso de especialización léxica en función del cual la significación partitiva ha quedado permanentemente ligada a una clase designativa en particular: la de las "personas que componen un grupo social":

(20) a. Sus gustos están condicionados por los de la mayoría;

b. Esto es lo importante en la política, y aunque parezca idiota - dijo burlón-, es lo democrático: aquí importa lo que dice o piensa la mayoría [Alan García (Perú): El mundo de Maquiavelo, Santafé de Bogotá, Tercer Mundo, 1994, p. 58, apud CREA].

La ganancia de entidad designativa se pone de manifiesto en su capacidad para recibir la caracterización de una amplia gama de adjetivos no determinativos (21); y, a pesar de que pueda parecer que también en estos casos resulta restituible el complemento encargado de expresar la totalidad fraccionada, lo cierto es que entonces la unidad que interviene es el puro cuantificador del que ahora nos ocupamos, y que, como veremos enseguida ( $\$ 3.4)$, tiene fuertemente restringida la posibilidad de llevar subordinados adjetivos "calificativos" (22):

(21) a. Sus gustos están condicionados por los de la influyente mayoría;

b. Aquí importa lo que dice o piensa la todopoderosa mayoría;

(22) a. ??Sus gustos están condicionados por los de la influyente mayoría de las personas;

b. ??Aquí importa lo que dice o piensa la todopoderosa mayoría de la gente.

En fin, como sustantivo designativo léxicamente asociado a la clase de las "personas", mayoría ya no puede quedar reemplazado por la expresión (la) mayor parte sin que de ello se deriven importantes cambios en la sustancia de contenido: Le preocupa demasiado la opinión de la mayoría $\neq$ Le preocupa demasiado la opinión de la mayor parte.

Volviendo a su faceta de cuantificador y a las estructuras a que da lugar, debe destacarse que el sustantivo complementario - encargado de expresar la totalidad - no incorpora a veces el artículo, sin que por ello se vea afectada la relación semántica partitiva. Se obtienen de este modo secuencias que, a pesar de estar censuradas normativamente (DPD: s. v. el, § 8; NGLE: 1060, 1451$1452,1537)$, no pueden ser tachadas de infrecuentes o extrañas:

(23) a. La mayoría de compañías — explicó Laporta - establecen un precio por debajo de la tarifa [La Vanguardia, 29/12/1994, apud CREA];

b. La niñera, menos discreta y más dada a la lamentación y al drama, dejaba caer de vez en cuando algunas alusiones a su incierto futuro económico o a la maldad congénita e irreversible de la mayoría de seres humanos [Cristina Fernández Cubas: Mi hermana Elba, Barcelona, Tusquets, 1981, p. 64, apud CREA]; 
c. Los empleados públicos esperan una respuesta positiva por parte del mandatario, ya que de no ser así la gran mayoría de estudiantes no contarán con todos sus útiles escolares y mucho menos con uniformes para asistir a clases [La Voz de Galicia, 15/1/2004, apud CREA].

A propósito de ellas, en la $N G L E$ (p. 1060) se sostiene lo siguiente:

[...] se observa que la omisión del artículo no implica en estos casos la conversión de la construcción partitiva en pseudopartitiva. Cabe pensar, por el contrario, que el rasgo de definitud presente en la mayoría es el que activa, en la conciencia lingüística de algunos hablantes, la supresión del artículo en la coda partitiva (la mayoría de las propiedades > la mayoría de propiedades) de forma similar a como lo hace en las relativas especificativas preposicionales: el libro con $\underline{\text { el }}$ que estudio > el libro con que estudio).

Y algo más adelante (ibíd.: 1537) se añade otra hipótesis explicativa:

Aunque pudiera pensarse que la omisión del artículo convierte la construcción partitiva en pseudopartitiva, no se obtiene el significado que corresponde a esta última. En cualquier caso, puede haber influido en el proceso el que los sustantivos fraccionarios, que solo admiten la construcción partitiva (un tercio de los ciudadanos), se asimilen en la conciencia lingüística de algunos hablantes a los numerales colectivos, que admiten la pseudopartitiva (un millón de ciudadanos).

Aunque no tanto en la justificación del fenómeno, sí coincidimos con la RAE y la ASALE en que tales estructuras, en relación con las correspondientes con artículo, no presentan cambios en el contenido que conforman (24a). En consecuencia, parece que podría llegar a considerárselas meras variantes de expresión (Hjelmslev, 1943: cap. XIV). Si en este plano resulta posible prescindir del significante del artículo es, seguramente, por la condición de partitivo léxico de mayoría. De hecho, el mismo fenómeno se documenta, por ejemplo, con los también partitivos totalidad o resto (24b). Opuestamente, no sucede lo mismo con otros cuantificadores carentes de dicho rasgo léxico y que, a diferencia de los partitivos mencionados, son también compatibles con complementos del nombre cuantitativos, de suerte que el artículo actúa como un elemento discriminador de estructuras cuya manifestación no puede obviarse (25):

(24) a. La mayoría de matriculados son mayores de treinta años (三 La mayoría de los matriculados son mayores de treinta años);

b. Les entregarán un juguete a \{la totalidad / el resto $\}$ de niños del centro (三Les entregarán un juguete a \{la totalidad / el resto $\}$ de los niños del centro);

(25) Se presentó en casa con una docena de cuadernos robados ( $\neq$ Se presentó en casa con una docena de los cuadernos robados).

De todas maneras, hay contextos sintácticos en los que la forma del artículo debe explicitarse, de manera que no se produce esa suerte de "neutralización" 
entre el complemento partitivo y el no partitivo ${ }^{12}$ a que suele dar lugar la semántica del cuantificador mayoría. Esto sucede, sin ir más lejos, cuando el sustantivo complementario está cuantificado:

(26) a. La mayoría de los muchos grupos que se inscribieron finalmente no se presentaron ( $\neq *$ La mayoría de muchos grupos que se inscribieron finalmente no se presentaron);

b. Su número circense gustó a la mayoría de los doce jueces ( $\neq$ Su número circense gustó a la mayoría de doce jueces).

En realidad, los complementos del nombre que intervienen en las secuencias destacadas en (23) informan sobre la composición de la parte referida por la mayoría, pero, dada la necesaria homogeneidad de clase designativa entre parte y todo, dan cuenta al mismo tiempo de la composición de la totalidad. De ahí la antedicha "neutralización" de estructuras. Ahora bien, desde el momento en que el sustantivo complementario va cuantificado, como sucede en (26), deja de resultar indistinta la caracterización de la parte segregada o del todo fraccionado, y se torna nuevamente pertinente la oposición entre complemento partitivo y no partitivo.

Tampoco la tematización del complemento admite la "variante" con el significante del artículo elidido, lo cual revela que dicho complemento no es en realidad un genuino partitivo desde el punto de vista sintáctico $^{13}$ :

(27) La mayoría de (los) matriculados son menores de treinta años $\rightarrow\{$ De los matriculados / *De matriculados $\}$, la mayoría son menores de treinta años.

\subsection{Compatibilidad con adjetivos y matización de su significado cuantitativo}

Tal y como anunciamos con anterioridad, en su vertiente estrictamente cuantificadora, mayoría tiene muy restringida la posibilidad de llevar subordinados adje-

\footnotetext{
${ }^{12}$ No hablamos de complemento pseudopartitivo ni de construcción pseudopartitiva porque esta última denominación, tal y como se emplea en los actuales estudios lingüísticos del español (v.g., Escandell Vidal, 1995; Vos, 2002; Gutiérrez Rodríguez, 2008; Demonte y Pérez-Jiménez, 2015), acoge en su referencia estructuras diversas que, no obstante, han permanecido indiferenciadas debido a su similar distribución de componentes semántico-pragmáticos ('cuantificador + de + cuantificado'): por un lado, grupos nominales con complemento del nombre en los que el cuantificador - de categoría sustantiva - es el núcleo sintáctico, a pesar de su precariedad designativa: una docena de libros, dos centenares de víctimas, una avalancha de mensajes...; de otra parte, grupos nominales en los que el cuantificador - en verdad adverbio, no obstante su apariencia sustantivase subordina sintácticamente a su cuantificado: cantidad de sueño 'mucho sueño', la tira de problemas 'muchos problemas', un huevo de reclamaciones 'muchas reclamaciones', la mitad de artículos, el triple de años (San Julián Solana, 2013: § 2.3 .1 y 2.3.3; íd., 2018b).

${ }^{13}$ Sobre las posibilidades de tematización de los complementos partitivos, "pseudopartitivos" y "falsos partitivos", cfr. Gutiérrez Rodríguez (2008: cap. 7, § 4.1.2). Para el concepto de "tematización', cfr. Fernández Lorences (2010).
} 
tivos pertenecientes a la amplia y heterogénea subcategoría de los tradicionales "calificativos". Solo acepta unos pocos - del tipo de gran(de), inmensa, enorme, vasta, holgada o abrumadora, a los que cabe sumar práctica-, todos ellos orientados a matizar su significación cuantitativa ${ }^{14}$. Los primeros (casi todos adjetivos de tamaño) informan, por lo general desde la anteposición, de que la parte segregada cumple holgadamente con la condición de ser la mayor en relación con el conjunto de las demás diferenciadas en la unidad sometida a fracción, hasta el punto de que sus límites extensionales se aproximan a los de la totalidad:

(28) a. [...] es algo que se creen a pies juntillas la gran mayoría de los españoles comprendidos entre Antequera y el Páramo de Masa y entre Aragón y el Finisterre [La Voz de Galicia, 15/1/2004, apud CREA]; b. Pero la inmensa mayoría de la población española está muy lejos de esos ideales [Triunfo, 16/7/1977, apud CREA];

c. Para la enorme mayoría de los jóvenes españoles y de las familias con menores ingresos, la vivienda se ha convertido en un bien prácticamente inaccesible [El Socialista, 4/2003, n. ${ }^{\circ}$ 651, apud CREA];

d. Los logotipos de Coca Cola y Pepsi Cola son reconocidos instantáneamente por la vasta mayoría de los habitantes del planeta [El Universal (Venezuela), 3/9/1996, apud CREA];

e. La holgada mayoría de los consumidores opina que los alimentos[,] junto con los hábitos alimenticios, influyen en gran medida en nuestra salud [CTIC-CITA, 27/2/2013].

f. La abrumadora mayoría de los jugadores de la selección nacional albanesa y de la Sub 21 no están dispuestos a volver a su convulsionado país [Clarín (Argentina), 3/4/1997, apud CREA].

No obstante la palmaria tendencia a la anteposición ${ }^{15}$, se han encontrado muestras en las que algunos de estos intensificadores de la significación cuantitativa se posponen a mayoría:

\footnotetext{
${ }^{14}$ La cuestión de la compatibilidad de las partitivas con distintos tipos de adjetivos ha sido recientemente abordada por Demonte y Pérez-Jiménez (2015: 32, 42) y Pérez-Jiménez y Demonte (2017: 361-362). Ahora bien, conviene no perder de vista que no todos los sustantivos partitivos presentan las mismas propiedades semánticas (San Julián Solana, 2016a), lo cual explica, a su vez, diferencias de tipo combinatorio entre unos y otros. Las propiedades de relación sintagmática de un sustantivo como tercio (numeral fraccionario carente del rasgo léxico 'pluralidad') no son extrapolables a mayoría (indefinido partitivo-proporcional portador del valor 'pluralidad').

${ }^{15} \mathrm{Tal}$ vez este hecho guarde relación con el general carácter restrictivo de los adjetivos pospuestos del español, los cuales conllevan, precisamente por ello, una presuposición de multiplicidad que entra en conflicto con la unicidad de lo significado por la mayoría en su faceta de cuantificador partitivo proporcional. Opuestamente, los adjetivos antepuestos no actúan a modo de restrictores, sino que destacan una propiedad que se presenta como inherente a lo referido por el sustantivo. Nótese que el grupo nominal los exploradores valientes presupone la existencia de otros exploradores que no poseen la cualidad significada por el adjetivo, algo que no sucede con los valientes exploradores.
} 
(29) a. La mayoría holgada de los hogares españoles agrupa todos sus servicios de telecomunicaciones en una única factura y proveedor [El Economista, 23/11/2017];

b. [...] el consumo cultural de la mayoría abrumadora de los habitantes de Carrasco está orientado hacia lo extranjero [Hugo Achugar (Uru-

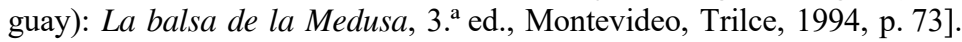

Aunque no guarde correspondencia alguna con ningún número natural, el que ahora nos ocupa es un cuantificador "objetivo" que, sin ser léxicamente preciso, sí es contextualmente precisable. Esto lo convierte en potencial destinatario de una matización aproximativa. No en vano, la frontera entre no ser la mayor de las partes diferenciadas en una unidad y sí serlo está perfectamente definida. Esta es la razón por la que mayoría acepta sin problemas la caracterización de práctica, que en cuanto adjetivo adverbial intensional (Pastor, 2016) - y, por tanto, necesariamente antepuesto - indica que el referente no satisface, por poco, las condiciones cuantitativas inscritas en el significado del sustantivo cuantificador; en otros términos, que la fracción denotada se aproxima a ser la de mayor tamaño - i. e., superior a la mitad-, pero no llega a serlo (aproximación por defecto) ${ }^{16}$ :

(30) a. Ha destacado que la práctica mayoría de los nuevos empleos han sido ocupados por varones [La Vanguardia, 23/10/2014] / *La mayoría práctica de los nuevos empleos han sido ocupados por varones;

b. En la Asamblea se encontraban la práctica mayoría de los presidentes de las Asociaciones de la Prensa de España [ABC, 17/11/1983, apud CREA] / *En la asamblea se encontraban la mayoría práctica de los presidentes.

Más allá de estos matizadores de su significación cuantitativa, rechaza intervenir como funtivo constante en una relación de dependencia con adjetivos no determinativos:

(31) a. ??Para la desesperada mayoría de los jóvenes españoles, la vivienda se ha convertido en un bien prácticamente inaccesible;

b. ??Los logotipos de Coca Cola y Pepsi Cola son reconocidos instantáneamente por la maleable mayoría de los habitantes del planeta;

c. ??La soñadora mayoría de los jugadores de la selección nacional albanesa y de la sub-21 no están dispuestos a volver a su convulsionado país.

Ahora bien, tal y como se anunció previamente (§ 3.2), la gama de adjetivos, así como sus posibilidades posicionales, se ve ampliada cuando mayoría, aun llevando un complemento de apariencia partitiva, recibe la determinación de una:

16 Los diccionarios consultados ( $D L E, D U E, D E A, D P D)$ no dan cuenta de este valor del adjetivo práctico, que también se registra con el partitivo impropio totalidad (San Julián Solana, 2016a: $§ 6.2 .1)$. 
(32) a. [...] una mayoría aterradora de los presidentes han sido abogados [NCE];

b. La mayoría (*aterradora) de los presidentes han sido abogados;

(33) a. [...] hay una mayoría clarísima de la sociedad catalana que quiere ser consultada [NCE];

b. La mayoría ( ${ }^{*}$ clarísima) de la sociedad catalana quiere ser consultada;

(34) a. [...] una mayoría creciente de los votantes peronistas están en contra de las políticas que hoy se están aplicando $[<\mathrm{https}: / /$ abelfer.wordpress.com/ 2016/03/06/la-batalla-del-si-y-del-no/>];

b. La mayoría (*creciente) de los votantes peronistas están en contra de las políticas que hoy se están aplicando.

(35) a. Una mayoría desconcertante de los centros de decisión en nuestras sociedades no acaba de creerse uno de los descubrimientos más importantes de la neurología moderna [NCE].

b. La mayoría (*desconcertante) de los centros de decisión no acaba de creerse uno de los descubrimientos más importantes de la neurología moderna.

Las muestras de (32a) y (35a) ponen de manifiesto que en estas circunstancias pueden tener cabida incluso adjetivos cuyo aporte semántico no persigue una matización cuantitativa, lo cual debe hacernos pensar acerca de si en estos casos nos hallamos realmente ante el puro cuantificador. Por lo demás, tampoco ahora es susceptible de recibir la caracterización del adjetivo adverbial intensional práctica:

(36) *Una práctica mayoría de los libros fueron quemados.

\subsection{Concordancia}

En lo tocante a las pautas de concordancia, mayoría se asimila al resto de cuantificadores propios netamente sustantivos (San Julián Solana, 2018a). Así, cuando aparece formando grupo nominal con un sustantivo en plural (el encargado de denotar la totalidad considerada), y dicho conjunto sintagmático desempeña la función de sujeto léxico, el verbo suele poder reiterar, bien el morfema de número del núcleo sintáctico (mayoría) (37), bien el del sustantivo complementario, que es el núcleo semántico de la estructura, en cuanto depositario de la mayor carga referencial (ejs. 38) ${ }^{17}$. Por el contrario, si la expresión

${ }^{17}$ Sobre el bloqueo de la doble opción de concordancia producido en ciertas oraciones con atributo (La mayoría de los soldados \{ ${ }^{*}$ es americana / son americanos\}) o con atributivo del sujeto (La mayoría de los vasos (*llegó rota / llegaron rotos\}), cfr. San Julián Solana (2018a: § 10). Para las restricciones a esta doble posibilidad motivadas por predicados que reclaman como argumentos una pluralidad, cfr. Demonte y Pérez-Jiménez (2015: 67-68) y Pérez-Jiménez y Demonte (2017: § 4.2). 
de la totalidad fraccionada corre a cargo de un colectivo en singular, las posibilidades de que el verbo adopte el morfema de 'plural' quedan restringidas a las particulares condiciones en las que los colectivos pueden desencadenar la concordancia ad sensum (San Julián Solana, 2016b: § 3.2.2) (39):

(37) a. La mayoría de los maltratadores condenados no ve delito en sus actos [Las Provincias, 25/10/2014];

b. La mayoría de los empresarios prepara ajustes pero sin despidos [Clarín (Argentina), 26/10/2014];

c. De sus pistolas salió la mayoría de las balas que segaron la vida de más de un centenar de manifestantes [La Nueva España, 23/1/2011];

(38) a. En el este de Ucrania, la mayoría de los votantes sólo sueñan con la paz [Investing, 26/10/2014];

b. La mayoría de los turistas de Nueva York se van temprano [Esmeralda Santiago (Puerto Rico): El sueño de América, Barcelona, Mondadori, 1996, p. 48, apud CREA];

c. Durante esta época, que comenzó hace 35,4 millones de años, desaparecieron la mayoría de los mamíferos arcaicos de las primeras épocas del cenozoico [Enciclopedia Encarta: s. v. Paleontología, apud CE];

(39) a. Los músicos más ancianos permanecen al lado de la figura del director mientras la mayoría de la orquesta descansa bebiendo y fumando en un pequeño bar [Argenpress Cultural, 13/2/2014] / * La mayoría de la orquesta descansan;

b. Entre 1938 y 1945 se convirtió en capital provincial del III Reich, periodo durante el cual desapareció la mayoría de la población judía [Enciclopedia Encarta: s. v. Viena, apud CE] / *Desaparecieron la mayoría de la población judía.

Tal y como ilustran los ejemplos de (37) y (38) - y en consonancia con los datos arrojados por el análisis cuantitativo de Pérez-Jiménez y Demonte (2017: 361) - la posición del grupo partitivo respecto del verbo no es un factor que condicione la alternancia numérica de este último; antes bien, en ambos casos predomina el plural (Demonte y Pérez-Jiménez, 2015: 31).

Siempre y cuando mayoría esté usado como puro cuantificador, poco importa que el complemento no manifieste el significante del artículo. De hecho, tal y como constatan Demonte y Pérez-Jiménez (2015: 36-37), el plural verbal continúa siendo la opción predominante cuando la función de sujeto es desempeñada por uno de estos grupos en los que el carácter escueto del sustantivo complementario no arruina la relación semántica partitiva, dadas las propiedades léxicas del núcleo. La apreciación de Fält (1972: 132) de que cuando "el complemento contiene un sustantivo que no va precedido de artículos, demostrativos o posesivos [...] admite más fácilmente la concordancia formal que el tipo con artículo" nos resulta, pues, imprecisa, y es consecuencia de no distinguir los casos de los que nos estamos ocupando —en los que mayoría está destinado a segregar una parte de una totalidad homogénea respecto de la clase 
designativa de sus componentes - de los que centrarán nuestra atención en el apartado siguiente $(\S 4)$ - en los que mayoría es un designador que, debidamente actualizado, denota una pluralidad de entes concebida como una de las partes de una totalidad internamente heterogénea en cuanto a la clase de sus integrantes- - Los siguientes ejemplos, en los que mayoría interviene en calidad de elemento cuantificativo, tratan de ilustrar que el plural verbal no se ve en absoluto obstaculizado por la ausencia de artículo ( $u$ otra unidad que comprenda su valor de 'identificabilidad') en el complemento:

(40) a. Entonces, la mayoría de programas se crearon con un formato de fecha que solo permitía dos golpes de teclado para la casilla de los años [Prensa Libre (Costa Rica), 3/5/1998, apud CE];

b. La mayoría de Unidades de Cardiología utilizan estos procedimientos $[A B C, 11 / 8 / 1995]$;

c. [...] la mayoría de incendios sucedieron dentro de las áreas protegidas [La Hora (Guatemala), 30/5/1998, apud CE].

El plural en el verbo sigue resultando perfectamente viable aun cuando el sustantivo destinatario de la aplicación semántica del cuantificador no se explicita bajo la forma de complemento del nombre por estimarse recuperable del contexto precedente o de la información situacional:

(41) a. [...] a mí me encanta ver lápidas: "Aquí yace fulanito", "Mi hijo más querido", "A una madre como tú", etc. Claro que mis preferidas son las de los niños porque la mayoría tienen la fotico pegada sobre el mármol y unas tienen cajitas musicales para que se arrullen los angelitos entre esos huecos tan feos [Wilson García A. (Colombia): "Huesitos", <http://home.cc.umanitoba.ca/ fernand4/atrasados.html>];

b. Existen distintos tipos de sismógrafos, pero la mayoría dependen, de alguna forma, del principio del péndulo [Enciclopedia Encarta: s. v. sismógrafo, apud CE].

Por lo que respecta a las razones que explican el fenómeno de la doble pauta de concordancia en la relación sujeto-verbo a que dan lugar los sustantivos cuantificadores en singular aplicados a un sustantivo en plural, es una cuestión de la que nos ocupamos pormenorizadamente en otro trabajo (San Julián Solana, 2018a). Allí sostenemos que el plural verbal no es fruto de reemplazar la estricta concordancia por la rección, tal y como se ha propuesto desde el paradigma funcionalista (Martínez, 1999: 2700-2701, 2746; Martínez García, 2007: 185). Tampoco creemos que cada tipo de concordancia se corresponda con una distinta estructura del grupo nominal sujeto, cuyo núcleo sintáctico sería en unos casos el elemento que denota la parte (cuando el verbo se presenta en singular), y en otros, el encargado de denotar la totalidad (cuando el núcleo oracional toma el 'plural' morfemático). En dicha línea de análisis - según la cual los elementos que intervienen como primer término en las construcciones (pseudo)partitivas 
son ambiguos entre un estatus referencial/léxico y otro no referencial/funcional o, a lo sumo, semiléxico- se incardina el estudio que lleva a cabo Rodrigues (2011) de las partitivas del portugués de Brasil con majoria, unidad esta que unas veces sería núcleo de un SN y otras, un "cuantificador" (entendido en términos categoriales, no semánticos, como aquí hacemos $)^{18}$. Tampoco estamos plenamente de acuerdo con aquellos otros autores que atribuyen las oscilaciones en el patrón de concordancia a las propiedades léxico-semánticas (intrínsecas o contextualmente adquiridas) de la "cabeza", que en todos los casos constituiría el término con el que concierta el verbo; desde dicha perspectiva, el plural verbal iría fatalmente asociado a una lectura distributiva/cuantificada/(sub)atómica de la construcción, mientras que la lectura colectiva/de grupo (concomitante) impondría el singular (cfr. Demonte y Pérez-Jiménez, 2015: 53-72; Pérez-Jiménez y Demonte, 2017: § 4) $)^{19}$.

En nuestra opinión, la llamada concordancia “ad sensum” que suelen suscitar los sustantivos cuantificadores aplicados a un sustantivo plural constituye un desplazamiento en el polo de concordancia desde el núcleo sintáctico del grupo nominal (en los casos que nos ocupan, mayoría) al sustantivo complementario - con independencia de que se materialice o no en el plano de expresión-, que es el que informa sobre la clase designativa del referente. El desarrollo del fenómeno es posible porque en español la concordancia conoce dos funciones: una general (facilitar la identificación de un referente) y otra específica (servir de índice funcional positivo del [núcleo] del sujeto). Dada la particular configuración interna de los grupos partitivos y cuantitativos desarrollados sobre la base de sustantivos cuantificadores (nótese que en ellos el núcleo sintáctico y el semántico no se identifican), ambas funciones de la concordancia alternan, en lugar de producirse el forzoso solapamiento habitual. Esto explica por qué fuera del marco de la construcción sintáctica de sujeto - o de alguna de las directamente relacionadas con ella (atributo y atributivo) - es el sustantivo que denota la totalidad e informa sobre la clase del referente el que comanda las relaciones de concordancia del grupo nominal. Véase, a este particular, el contraste entre (42a) y (42b):

\footnotetext{
${ }^{18}$ El recurso a la naturaleza híbrida entre lo referencial/léxico y lo no referencial/funcional lo encontramos también, aplicado ya a la concordancia de los grupos (pseudo)partitivos del español, en los trabajos de Vos (2002) y Gutiérrez Rodríguez (2008). Cuestión distinta es que algunos sustantivos con una faceta propiamente cuantitativa también conozcan empleos designativos —el que estamos estudiando supone una buena muestra-, pero en cuanto designadores ya no nuclean verdaderas construcciones partitivas.

19 Aunque no compartimos la idea de una correspondencia sistemática en ninguno de ambos casos, sí reconocemos que el singular verbal tiende a favorecer la lectura colectiva o de grupo concomitante, y el plural la distributiva o (sub)atómica (San Julián Solana, 2016a: §10.4.3.2 y 2018a: $§ 9.2)$.
} 
(42) a. La mayoría de los langostinos \{procede/proceden\} de Madagascar; b. La mayoría de los langostinos $\left\{{ }^{*} \mathrm{la} / \mathrm{los}\right\}$ traen de Madagascar.

\section{Mayoría, SUSTANTIVO COLECTIVO}

\subsection{Significación}

En los siguientes ejemplos, el sustantivo mayoría cuenta con un significado distinto al que exhibía en los enunciados estudiados en el apartado precedente, si bien esta diferencia no resulta en absoluto palmaria debido a que la noción de 'parte' permanece en su lexema (de hecho, que sepamos, no ha sido puesta de relieve con anterioridad):

(43) a. El grupo se compone de una mayoría de estudiantes, unos pocos profesores y algún padre;

b. Si el Tribunal hubiera estado constituido por una mayoría de fariseos, posiblemente las cosas habrían sido muy distintas y Jesús habría terminado su vida apedreado o estrangulado [Juan José Benítez: Caballo de Troya 1, Barcelona, Planeta, 1994, p. 351];

c. Esas viviendas están habitadas por una mayoría de gente humilde.

En dichas oraciones, el sustantivo transpuesto por la preposición de - que ha de aparecer desprovisto de artículo u otro actualizador y ser portador de una pluralidad (morfológica o léxica) - no lleva a cabo la denotación del todo fraccionado, sino que especifica la clase a la que pertenecen los componentes de la pluralidad a la que se refiere mayoría, que en estos casos gana entidad designativa y se aleja de la estricta cuantificación ${ }^{20}$. Por lo tanto, dentro del grupo sintagmático sustantivo no se hace mención a la totalidad, que simplemente queda presupuesta y debe ser recuperada del contexto o de la situación por el destinatario del mensaje. Esta totalidad se presenta como internamente heterogénea, constituida por ejemplares de diversas (sub)clases, al contrario de lo que sucede con las estructuras partitivas a que da lugar mayoría en su vertiente estrictamente cuantitativa:

(44) a. En el nuevo grupo de investigación hay una mayoría de profesores [también hay individuos de otra(s) clase(s)];

b. En el nuevo grupo de investigación hay una mayoría de profesores titulares [puede que la totalidad se complete con profesores no titulares, que lo haga con ellos y con personas pertenecientes a otros colectivos, o sencillamente que no haya ningún otro tipo de profesor $^{21}$ ].

\footnotetext{
${ }^{20}$ En consecuencia, no deben confundirse estos complementos con los que, subordinados al cuantificador mayoría, siguen contribuyendo a la expresión de una relación del tipo 'parte-todo' a pesar de carecer del artículo —o de alguna otra unidad con el valor de 'identificabilidad'— (§ 3.3).

${ }^{21}$ Los siguientes ejemplos ilustran esas posibilidades: a) En el nuevo grupo de investigación hay una mayoría de profesores titulares y algún que otro asociado; b) En el nuevo grupo de
} 
Si como cuantificador - $\mathrm{y}$ precisamente por ello- estaba dotado de una acusadísima capacidad fórica (o mostrativa), no sucede lo mismo en los casos que ahora nos ocupan, más allá de la mera evocación de una totalidad. Esto se traduce en la imposibilidad de que la especificación de la clase de los componentes que integran la pluralidad denotada por mayoría venga de la mano de un sustantivo tematizado:

(45) *(De) personas con sobrepeso, en las grandes ciudades hay una mayoría.

Por lo demás, ha de presentarse sin el antedicho complemento del nombre cuando se predica del sujeto - especialmente, privado de actualizador (46a), si bien este puede ir exigido por un restrictor subsiguiente (46b)-:

(46) a. Los extranjeros son (una) mayoría en mi nueva comunidad de vecinos; b. Los católicos son una mayoría poco fervorosa [El Tiempo (Colombia), 24/12/2011] / *Los católicos son mayoría poco fervorosa.

\subsection{Compatibilidad con adjetivos no determinativos}

Un aspecto interesante, por cuanto muestra el carácter designativo que posee aquí mayoría, es el hecho de que la especificación de la clase a la que pertenecen los integrantes de la pluralidad denotada, que generalmente corre a cargo de un complemento del nombre, puede venir dada por un adjetivo no determinativo - concretamente, del tipo de los relacionales (Pastor, 2016) - , si es que existe en el acervo léxico del español:

(47) a. El Congreso está dominado por una mayoría de conservadores $\rightarrow \mathrm{El}$ Congreso está dominado por una mayoría conservadora;

b. En el pasado estuvo controlado por una mayoría de socialistas $\rightarrow$ En el pasado estuvo controlado por una mayoría socialista;

c. En el grupo de trabajo recién constituido hay una mayoría de estudiantes y solo cinco profesores $\rightarrow$ En el grupo de trabajo recién constituido hay una mayoría estudiantil y solo cinco profesores.

A propósito, la gama de adjetivos que puede tomar ahora como adyacentes nominales, tanto antepuestos como pospuestos, resulta mucho más amplia y variada que la limitadísima serie de "matizadores" que toleraba como cuantificador ${ }^{22}(\S 3.4)$ :

investigación hay una mayoría de profesores titulares, algún que otro asociado y un par de becarios; c) En el nuevo grupo de investigación hay una mayoría de profesores titulares y unos pocos becarios.

${ }^{22}$ Ahora bien, ya no es potencial destinatario de la 'aproximación por defecto' del adjetivo intensional práctica: El Consejo está dominado por una (*práctica) mayoría de profesores díscolos; La asociación está controlada por la (*práctica) mayoría estudiantil a la que dio pie la nueva normativa. 
(48) a. En la región hay una \{sorprendente/increíble/perseguida/vapuleada/ denostada\} mayoría de personas cuya lengua materna es el aimara; b. En la región hay una mayoría \{importante/marginada/ninguneadal protegida\} de personas cuya lengua materna es el aimara.

\subsection{Concordancia}

Los datos que han ido exponiéndose revelan que mayoría cuenta en estos casos con una condición de designador de la que carecía en los usos analizados en $\S 3$, lo cual no hace sino recomendar su asimilación a la heterogénea clase semántica de los colectivos, dada la pluralidad léxica que entraña ${ }^{23}$. De todos modos, la vaguedad de la clase que designa (la de los "entes caracterizados por constituir la mayor parte de un todo heterogéneo en cuanto a la clase de sus integrantes") hace que el concurso de un complemento del nombre especificador resulte casi sistemático. Entonces, al entrar en la oración desde la función de sujeto léxico, el verbo puede, por lo general, reproducir el singular de mayoría o el plural morfológico de su adyacente:

(49) Una mayoría de profesores \{controla/controlan\} la Asamblea, por lo que las propuestas estudiantiles no suelen salir adelante.

Esto es algo que no debe causar sorpresa, pues la subordinación de un sustantivo morfológicamente pluralizado como complemento del nombre supone una de las limitadas condiciones bajo las cuales los colectivos pueden desencadenar la llamada concordancia "ad sensum" en los usos generales - ej.: Una familia de franceses \{fallecen/fallece\} en Murcia al estrellarse su avioneta (San Julián Solana, 2016b: §3.2.2) — o incluso adaptarse contextualmente como cuantificadores - ej.: Un enjambre de niños \{esperaban/esperaba\} en el patio (San

\footnotetext{
${ }^{23}$ No creemos que los "colectivos" constituyan una verdadera subcategoría funcional de sustantivo común (i. e., inscrita en la forma de contenido de la lengua). Si quiere verse en ellos una clase, esta tendrá que considerarse de tipo léxico-semántico, y estaría constituida por los sustantivos cuyo lexema designa conjuntos de entes de una determinada especie (claro está, los rasgos léxicos repercuten en la configuración sintagmática de los enunciados). Se trataría, en cualquier caso, de una clase semántica caracterizada por una acusada diversidad interna (lo cual equivale a hablar de varias clases, no de una sola), pues la pluralidad léxica que comportan sus integrantes puede tener un carácter muy distinto en unas unidades y en otras: junto a los colectivos que expresan 'totalidad' (humanidad, ciudadanía), mero 'agregado' de entes (rebaño, pinar) o 'pluralidad abundante' (muchedumbre, gentío), deben consignarse aquellos que sirven para denotar conjuntos con un número específico de miembros (pareja, cuarteto, tríada) (San Julián Solana, 2007; íd, 2013: § 4.7). Por eso los distintos colectivos responden de manera muy dispar a las "pruebas" con las que algunos autores, como Bosque (1999), pretenden justificar la pertinencia formal de la división individual/colectivo, pruebas que, más que revelar aspectos concernientes a la forma de contenido, ponen de manifiesto particularidades sustanciales que pertenecen al nivel variable de los usos (cfr. San Julián Solana, 2016a: § 5.2.5.4).
} 
Julián Solana, 2016b: $§ 4.2$ y 2019)—. Con todo, la observación de los corpus manejados parece indicar que la tendencia predominante es ahora la de que el verbo aparezca en singular, lo cual enlazaría con la apreciación de Fält (1972: 132) de que la falta de artículo (o una unidad con su valor de 'identificabilidad') en el complemento favorece "la concordancia formal" (aunque, recordemos, este autor no segrega los complementos sin artículo semánticamente partitivos).

Pero lo cierto es que, en ausencia del complemento del nombre - por ejemplo, cuando la precisión que efectúa llega de la mano de un adjetivo relacional-, mayoría revela la naturaleza eminentemente designativa que tiene en estos casos, y rechaza el plural en el núcleo de la oración, en lo que supone un nuevo punto de desencuentro con los empleos cuantificativos:

(50) *Una mayoría socialista controlaban el Congreso en aquel entonces.

$\mathrm{Y}$ a esto cabe sumar que fuera de la función de sujeto $-\mathrm{o}$ las directamente relacionadas con ella de atributo o atributivo del sujeto- el colectivo mayoría no encuentra impedimento para instituirse en término de concordancia (51), a diferencia del rechazo que exhibe el cuantificador (52):

(51) No sé qué hacer con los muchos alumnos que hablan en clase. ¡A esa mayoría \{cuchicheante / de cuchicheadores\} no hay quien la aguante!

(52) *No come langostinos porque la mayoría la traen de Madagascar.

\subsection{Compatibilidad con los distintos tipos de actualizadores}

Algunos de los ejemplos y comentarios previos han servido para anticipar otra de las cualidades que en esta faceta designativa tiene mayoría. Ahora ya no solo toma el artículo; al contrario, es un(o)/a/os/as el actualizador que más frecuentemente propicia el paso de la designación a la denotación (53). A decir verdad, el artículo no suele intervenir cuando el sintagma estudiado cuenta con este valor designativo, posiblemente para evitar equívocos y descartar la interpretación cuantitativa; esto no obsta para que aparezca (con una orientación catafórica) cuando un delimitador pospuesto - por ejemplo, una oración adjetiva - exige la marca de 'identificabilidad' (54). Y aunque se trate de una posibilidad poco explotada en los usos, resulta compatible con otro tipo de actualizadores (55). Es más, cuando la función sintáctica y el lexema verbal lo permiten, puede aparecer escueto (56):

(53) En su doble disco recopilatorio hay una mayoría de baladas, mientras que los números de baile y los medios tiempos son más bien escasos;

(54) a. Pretenden ser un instrumento útil para la mayoría ciudadana que quiere un cambio; 
b. En la asamblea intervienen alumnos, personal de la Administración y la mayoría de profesores a la que aludí con anterioridad;

(55) a. Esta mayoría de profesores se muestra totalmente intransigente con las iniciativas estudiantiles;

b. Muchos alumnos están realmente hartos de la Asamblea y de $s u$ limitante mayoría de profesores;

c. Creo que algo me ha comentado mi hijo de cierta mayoría de profesores que bloquea todas sus propuestas en la Asamblea;

d. En ambos grupos hay sendas mayorías de jubilados;

e. La sexualidad humana se parece a la de muchas otras especies animales cuyas crías son fertilizadas internamente y requieren cuidado biparental, difiriendo así de esa otra mayoría de especies cuyas crías son fertilizadas externamente y disfrutan sólo de cuidado uniparental o, incluso, de ningún cuidado en absoluto [NCE];

f. El mundo musulmán se divide en dos mayorías - los seguidores de Mahoma, que son los suniitas (1200 millones), y los seguidores de Ali, yerno de Mahoma, que son los chiitas (100 millones) - y hay otras minorías varias $[N C E$, con puntuación enmendada].

(56) a. Estos talleres [...] "están dirigidos a todas las personas $[\ldots] \mathrm{y}$, aunque siempre hay mayoría de mujeres, nos gustaría que los hombres participaran más", apunta Cendegui [Lanza Digital, 27/10/2014];

b. Los dos países están enfrentados por la región de Kosovo, que tiene mayoría de albaneses pero es aún considerada por Serbia como parte de su territorio [Clarín (Argentina), 16/10/2014];

c. Luanda presiona para que los armadores constituyan empresas mixtas con mayoría africana [La Voz de Galicia, 29/12/2004, apud CREA]; d. Los clientes que fuman son mayoría.

\subsection{Relación con los morfemas de número}

Se aprecia en los ejemplos de (55d) y (55f) que, aun tratándose de algo poco usual, mayoría pasa en estos casos a poder tomar el morfema de 'plural'. En el primero de los ejemplos mencionados, se hace referencia a la parte mayor de dos totalidades distintas. Por el contrario, en (55f) — también en (55e), por efecto del distributivo otra-, el sintagma analizado adopta el sentido de 'conjunto numeroso en relación con el total', que supone la anulación del valor superlativo y que, precisamente por ello, no lleva asociada la noción de 'unicidad'. Así, en (55f) mayorías denota dos partes que satisfacen la condición de ser copiosas en relación con la totalidad considerada, y que contrastan con otras menos nutridas, a las que se alude mediante minorías. 


\section{MAYORÍA, SUSTANTIVO INDIVIDUAL DESIGNATIVO}

\subsection{Significación}

Aunque en los siguientes ejemplos mayoría conserve en cierta medida la noción de 'partitividad', dista mucho de funcionar como una unidad cuantificadora:

(57) a. Las encuestas auguraban que la coalición gobernante perdería la mayoría [20 Minutos, 27/10/2014];

b. La propuesta de Iglesias para constituir Podemos gana por amplia mayoría con un 80,71\% [Público, 27/10/2014].

Se trata del "sentido "técnico"” del que habla Fält (1972: 133), que en realidad supone un caso de especialización léxica por el cual la información partitiva del cuantificador mayoría queda permanentemente asociada a una clase concreta de entes: la de los "votos reunidos en un escrutinio". De este modo, se constituye un sintagma que expresa el "mayor número de votos conformes en una votación' (DLE: s. v. mayoría). Ya no es que la unidad resultante de dicho proceso sea un inequívoco designador, sino que ni siquiera puede incluirse entre los colectivos.

5.2. Compatibilidad con actualizadores, adjetivos no determinativos y el morfema de 'plural'

En estos casos, mayoría presenta una gran tolerancia a diversos actualizadores (58), o incluso puede aparecer sin él, si la función sintáctica lo permite (59), al tiempo que gana capacidad tanto para combinarse con una amplia gama de adjetivos antepuestos y pospuestos (60) como para pluralizarse (61):

(58) a. La mayoría de la extrema derecha francesa ha hecho temblar los cimientos de media Europa;

b. Pocos esperaban esta mayoría socialista;

c. ¿Logrará el partido gobernante renovar su actual mayoría?;

d. En las próximas elecciones esperan obtener otra mayoría;

e. Después de sus dos mayorías, se retiró de la política;

(59) a. Es muy probable que esta petición sea rechazada el próximo martes en la mesa del Congreso, donde los populares y los nacionalistas tienen mayoría [La Vanguardia, 16/9/1995, apud CREA];

b. En lo que no hubo tanto acuerdo en la junta de portavoces fue en si el pleno debería ser el martes o el miércoles, aunque por mayoría se acordó que fuera el miércoles [La Vanguardia, 4/5/1994, apud CREA];

(60) a. La \{inesperada/abultada/sorprendente/anhelada\} mayoría que obtuvieron en las últimas elecciones no dejó indiferente a ningún sector de la sociedad; 
b. El recuento de votos terminó con una mayoría \{aplastante/muy escasa/holgada/insignificante/muy reveladora/dudosa/firme/contundente\} de los demócratas ${ }^{24}$;

(61) a. El secretario general del PSOE cree que en todas las democracias sensatas las mayorías se logran conservando el espacio de centro sin perder el de la izquierda [La Vanguardia, 23/6/1994, apud CREA];

b. Sin embargo, la explicación de esta distorsión — que ha facilitado las abultadas mayorías de UCD, las mayorías absolutas del PSOE y la influencia de los nacionalistas - no se encuentra en una sobrerrepresentación del mundo rural [La Vanguardia, 27/2/1994, apud CREA].

\subsection{Estructura del grupo nominal}

Evidentemente, la posibilidad de adoptar un complemento del nombre se mantiene, pero este no estará orientado a la expresión de la totalidad fraccionada - en suma, no será partitivo - ni tampoco a dar cuenta de la clase de los entes que componen la fracción diferenciada:

(62) a. Las encuestas indican que la mayoría del candidato progresista será aún mayor que hace cuatro años ['posesivo'];

b. Contra todo pronóstico, obtuvo una mayoría de impresión [三 impresionante];

c. Tratará de revalidar la mayoría de los pasados comicios ['origen', 'procedencia'].

\subsection{Concordancia}

Por lo que se refiere a la manera en que establece concordancia, las apreciaciones de Fält vuelven a resultar imprecisas. Afirma este autor que, con el valor de contenido que ahora nos ocupa, "el singular es relativamente más frecuente que el plural" (Fält, 1972: 133). Antes bien, lo que demuestran los hechos lingüísticos es que, al intervenir desde la función de sujeto (ya como sintagma, ya como funtivo constante de un grupo sintagmático sustantivo), el verbo solo cuenta con la posibilidad de reproducir su morfema de número, quedándole vedada la participación en el fenómeno de la concordancia ad sensum:

(63) Todos coincidimos en que esta mayoría de los independentistas en las últimas elecciones $\{$ ha sorprendido / *han sorprendido $\}$ a propios y extraños.

\footnotetext{
${ }^{24} \mathrm{Al}$ tomar, necesariamente pospuestos, adjetivos como absoluta, relativa (o simple), cualificada (también calificada y especial) o reforzada, se forman expresiones pertenecientes al tecnolecto electoral que designan distintas modalidades de mayoría.
} 
Y el mismo comportamiento se registra al abandonar el marco de la función de sujeto:

(64) La mayoría de los republicanos no se $\{1 \mathrm{l} / * \operatorname{los}\}$ imaginaba nadie.

\section{CONCLUSIÓN}

El análisis previo muestra que las distintas acepciones de mayoría en las que está presente el rasgo léxico de 'partitividad' llevan asociadas una serie de marcas formales. Estas guardan relación con la (in)tolerancia al morfema de 'plural', con el tipo de actualizadores que puede recibir, con los adjetivos no determinativos que admite como adyacentes, con la estructura de los grupos nominales a que da lugar y con las pautas de concordancia.

\begin{tabular}{|c|c|c|}
\hline $\begin{array}{l}\text { Cuantificador partitivo } \\
\text { proporcional }\end{array}$ & $\begin{array}{l}\text { signador del mayor } \\
\text { njunto de una totalidad } \\
\text { terogénea (colectivo) }\end{array}$ & $\begin{array}{l}\text { esignador del mayor } \\
\text { imero de votos conformes } \\
\text { una votación }\end{array}$ \\
\hline $\begin{array}{l}\text { - Solo recibe la determina- } \\
\text { ción del artículo: la (son } \\
\text { marginales los casos con una } \\
\text { y un complemento partitivo). } \\
\text { - Da lugar (como núcleo } \\
\text { sintáctico) a grupos partiti- } \\
\text { vos. } \\
\text { - Únicamente puede llevar } \\
\text { subordinados, preferible- } \\
\text { mente desde la anteposición, } \\
\text { unos pocos adjetivos no de- } \\
\text { terminativos destinados a ma- } \\
\text { tizar su significado cuanti- } \\
\text { ficacional (ej.: gran, inmen- } \\
\text { sa, enorme; práctica). (Se } \\
\text { exceptúan los antedichos ca- } \\
\text { sos con una, que admiten } \\
\text { más adjetivos y no ofrecen } \\
\text { especial resistencia a su pos- } \\
\text { posición.) } \\
\text { - En español estándar, no } \\
\text { pluralizable. } \\
\text { - Cuando interviene como } \\
\text { sujeto léxico y el sustantivo } \\
\text { al que se aplica semánti- } \\
\text { camente está morfológica- } \\
\text { mente pluralizado (con inde- } \\
\text { pendencia de que este se } \\
\text { explicite o no como comple- }\end{array}$ & $\begin{array}{l}\text { sos tipos de actualizador; } \\
\text { puede carecer de él. } \\
\text { - Incapaz de nuclear auténti- } \\
\text { cos grupos partitivos. Cuan- } \\
\text { do lleva complemento del } \\
\text { nombre, este suele indicar la } \\
\text { clase de los componentes de } \\
\text { la parte denotada, y es sus- } \\
\text { ceptible de ser sustituido por } \\
\text { un adjetivo relacional si exis- } \\
\text { te en el inventario léxico del } \\
\text { idioma. } \\
\text { - Tolera adjetivos no deter- } \\
\text { minativos, tanto antepuestos } \\
\text { como pospuestos, sin espe- } \\
\text { ciales restricciones. } \\
\text { - Acepta el plural morfoló- } \\
\text { gico, aunque no es usual que } \\
\text { incorpore dicho morfema. } \\
\text { - Cuando interviene en sin- } \\
\text { gular en calidad de sujeto y } \\
\text { se le subordina como com- } \\
\text { plemento del nombre un sus- } \\
\text { tantivo en plural, el verbo } \\
\text { puede adoptar cualquiera de } \\
\text { los dos términos del paradig- } \\
\text { ma morfológico de número } \\
\text { (con aparente predominio del }\end{array}$ & $\begin{array}{l}\text { - Vinculación léxica con la } \\
\text { clase de los "votos de un su- } \\
\text { fragio". } \\
\text { - Amplia tolerancia con los ac- } \\
\text { tualizadores, y también pue- } \\
\text { de carecer de él. } \\
\text { - Nunca nuclea construccio- } \\
\text { nes partitivas. Los comple- } \\
\text { mentos determinativos que } \\
\text { puede llevar subordinados } \\
\text { tampoco dan cuenta de la } \\
\text { composición de una parte se- } \\
\text { gregada. Con frecuencia, in- } \\
\text { dican 'posesión'. } \\
\text { - Acepta adjetivos no deter- } \\
\text { minativos tanto antepuestos } \\
\text { como pospuestos. } \\
\text { - Permite la pluralización. } \\
\text { - No da lugar a la llamada } \\
\text { concordancia "ad sensum": } \\
\text { si, en singular, desempeña la } \\
\text { función de sujeto léxico, el } \\
\text { verbo deberá presentarse } \\
\text { también en singular. En otros } \\
\text { contextos sintácticos, siem- } \\
\text { pre comanda las relaciones } \\
\text { de concordancia del grupo } \\
\text { nominal del que es funtivo } \\
\text { constante. }\end{array}$ \\
\hline
\end{tabular}


mento del nombre), el verbo puede presentarse tanto en singular como en plural (con predominio del plural). Fuera del ámbito de la función sintáctica de sujeto $-\mathrm{y}$, en ocasiones, también de las directamente relacionadas con él: atribut(iv)o-, la concordancia se establece con el sustantivo que expresa la totalidad, con independencia de que se haga o no explícito como complemento partitivo en el plano de expresión.

- Conmutable por la expresión partitivo proporcional (la) mayor parte (no en los casos con una). singular). Sin dicho complemento, solo tiene cabida el singular. En contextos sintácticos totalmente ajenos a la función de sujeto, es susceptible de intervenir como polo de concordancia con unidades externas al grupo nominal del que es núcleo sintáctico.

- No es conmutable por el cuantificador partitivo-proporcional (la) mayor parte.
- No resulta conmutable por la expresión partitivo-proporcional (la) mayor parte.

\section{CUADRO 1.-Rasgos formales que caracterizan las tres principales} acepciones de mayoría estudiadas ${ }^{25}$

Nuestro trabajo también pone de manifiesto la conveniencia de que los estudios lexicográficos y los gramaticales no discurran, como suele ser habitual, por caminos totalmente independientes.

En este sentido, la atención aquí prestada a los aspectos formales nos ha permitido distinguir dos acepciones - una en la que mayoría es un sustantivo cuantificador ( $\$ 3)$ y otra en la que se comporta como colectivo ( $(4)$ - allí donde los diccionarios, dado lo tenue de esta diferencia semántica, disciernen una sola: 'parte mayor de un conjunto de personas o cosas' (DLE: acep. 5; DUE: acep. 2; $D E A$ : acep. 1).

También hemos dado cuenta de un valor de contenido - el genérico cuasiuniversal asociado a registros de escasa formalidad: Desde que compró el coche, la mayoría han sido disgustos (§ 3.3) — del que no se informa ni en las obras lexicográficas ni tampoco en las gramaticales.

Pero al margen de este par de contribuciones concretas, lo cierto es que toda la batería de rasgos morfosintácticos diferenciales que se ha ido ofreciendo

\footnotetext{
${ }^{25}$ No se incluye el sentido "genérico" ligado a registros coloquiales que adquiere el cuantificador cuando carece de orientación fórica o mostrativa (Desde que te mudaste, la mayoría han sido problemas) ni el significado con el que pasa a vincularse con la clase de las "personas [que conforman un determinado grupo social]" (Para mi hermano, la opinión de la mayoría siempre ha sido un lastre) (§ 3.3).
} 
puede resultar provechosa en el campo de la lexicografía. Especialmente en estos tiempos, en los que el soporte digital hace perfectamente viable el enriquecimiento de las definiciones con información gramatical. La incorporación de este tipo de datos no solo redundaría en un reforzamiento de las distinciones semánticas establecidas en la formulación de las diversas acepciones, sino que haría de los diccionarios herramientas mucho más potentes de lo que lo son hoy desde una perspectiva onomasiológica.

La explicitación de marcas formales asociadas a determinados valores sustanciales también puede resultar de gran provecho en otro ámbito: el de la enseñanza del español, especialmente (aunque no solo) a hablantes que no lo tienen por lengua materna.

En fin, las distinciones novedosas aquí efectuadas - sobre todo la que revela la heterogeneidad subyacente a la acepción 'parte mayor de un conjunto de personas o cosas' - pueden rentabilizarse en ulteriores trabajos de corte cuantitativo, ya que cualquier tentativa en esta dirección carece de validez si concede un tratamiento unitario a unidades de naturaleza diversa ${ }^{26}$.

\section{BIBLIOGRAFÍA}

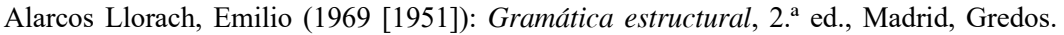

Alarcos Llorach, Emilio (1994): Gramática de la lengua española, Madrid, Espasa Calpe.

Alcina Franch, Juan y José Manuel Blecua (1998 [1975]): Gramática española, 10.a ed., Barcelona, Ariel.

Alonso, Amado y Pedro Henríquez Ureña (1969 [1938]): Gramática castellana. Primer curso, 25. a ed., Buenos Aires, Losada.

Alonso, Amado y Pedro Henríquez Ureña (1969 [1939]): Gramática castellana. Segundo curso, 23. ${ }^{\text {a }}$ ed., Buenos Aires, Losada.

Bello, Andrés (1981 [1847]): Gramática de la lengua castellana destinada al uso de los americanos, en Rafael Caldera (dir.), Obras completas de Andrés Bello, 2. ${ }^{a}$ ed., Caracas, Fundación La Casa de Bello, vol. IV.

Bosque, Ignacio (1980): Problemas de morfosintaxis, Madrid, Universidad Complutense.

Bosque, Ignacio (1999): “El nombre común”, en Ignacio Bosque y Violeta Demonte (dirs.), Gramática descriptiva de la lengua española, Madrid, Espasa Calpe, I, pp. 3-75.

Bosque, Ignacio y Violeta Demonte (dirs.) (1999): Gramática descriptiva de la lengua española, Madrid, Espasa Calpe.

Brucart, José M. (1997): "Concordancia ad sensum y partitividad en español”, en Manuel Almeida y Josefa Dorta (eds.), Contribuciones al estudio de la lingüística hispánica. Homenaje al profesor Ramón Trujillo, Barcelona, Montesinos, I, pp. 157-183.

Brucart, José M. (1999): "La elipsis”, en Ignacio Bosque y Violeta Demonte (dirs.), Gramática descriptiva de la lengua española, Madrid, Espasa Calpe, II, pp. 2787-2863.

${ }^{26}$ Por tratarse de una estructura particular de la que no participa solo mayoría, y dadas las limitaciones de espacio, posponemos la presentación de los datos referidos a la secuencia en $s u$ mayoría —o, más concretamente, "en + adj. posesivo concordado + mayoría"—, análoga a otras como en su totalidad o en su mayor parte. 
Cardinaletti, Anna y Giuliana Giusti (2006): "The Syntax of Quantified phrases and quantitative clitics", en Martin Everaert y Henk Van Riemsdijk (eds.), The Blackwell companion to syntax, Oxford, Blackwell, pp. 23-93.

$C E$ = Davies, Mark (2002-): Corpus del Español: 100 million words, 1200s-1900s, <https:// www.corpusdelespanol.org/hist-gen/>.

CORPES XXI = Real Academia Española: Banco de datos (CORPES XXI) [en línea]. Corpus del Español del Siglo XXI (CORPES), <http://www.rae.es>.

$C R E A=$ Real Academia Española: Banco de datos (CREA) [en línea]. Corpus de referencia del español actual, <http://www.rae.es>.

DEA = Seco, Manuel, Olimpia Andrés y Gabino Ramos (1999): Diccionario del español actual, Madrid, Aguilar.

Demonte, Violeta e Isabel Pérez-Jiménez (2015): "Construcciones partitivas y pseudopartitivas en español: concordancia híbrida y variación en la interficie sintaxis-semántica", en Esther Hernández y Pedro Martín Butragueño (eds.), Variación y diversidad lingüística: hacia una teoría convergente, México D. F., El Colegio de México/Centro de Estudios Lingüísticos y Literarios, pp. 15-98.

$D L E=$ Real Academia Española y Asociación de Academias de la Lengua Española (2014): Diccionario de la lengua española [en línea], 23. ${ }^{\text {a }}$ ed., Madrid, Espasa, <http://dle.rae.es/>.

$D P D=$ Real Academia Española y Asociación de Academias de la Lengua Española (2005): Diccionario panhispánico de dudas, Madrid, Santillana.

DUE = María Moliner (2008): Diccionario de uso del español, DVD, 3. ${ }^{\mathrm{a}}$ ed., Madrid, Gredos.

Escandell Vidal, M. Victoria (1995): Los complementos del nombre, Madrid, Arco/Libros.

Fält, Gunnar (1972): Tres problemas de concordancia verbal en el español moderno, Uppsala, Almqvist \& Wiksell.

Fernández Lorences, Taresa (2010): Gramática de la tematización en español, Oviedo, Universidad de Oviedo.

Fernández Ramírez, Salvador (1987 [1951]): Gramática española. Vol. 3.2. El pronombre, 2. ${ }^{\text {a }}$ ed., Madrid, Arco/Libros.

Gutiérrez Rodríguez, Edita (2008): Rasgos gramaticales de los cuantificadores débiles, tesis doctoral, Madrid, Universidad Complutense de Madrid.

Hjelmslev, Louis (1943): Prolegómenos a una teoría del lenguaje, 2. a ed., Madrid, Gredos, 1974.

Kany, Charles E. (1969 [1963]): Sintaxis hispanoamericana, Madrid, Gredos.

López Palma, Helena (2011): "Algunas condiciones impuestas por el sustantivo sobre la alternancia artículo determinado/artículo indeterminado", en M. Victoria Escandell Vidal, Manuel Leonetti y Cristina Sánchez López (eds.), 60 problemas de gramática, Madrid, Akal, pp. 46-53.

Martinet, André (1974 [1960]): Elementos de lingüística general, Madrid, Gredos, 1974.

Martínez, José A. (1994): Funciones, categorías y transposición, Madrid, Istmo.

Martínez, José A. (1999): "La concordancia en español", en Ignacio Bosque y Violeta Demonte (dirs.), Gramática descriptiva de la lengua española, Madrid, Espasa Calpe, II, pp. 26952786.

Martínez, José A. (2013): "Cuantificación y clasificación en los grupos nominales del español", en Daniel A. García Velasco, Santiago González, Francisco Martín Miguel, Ana Isabel Ojea López, Rodrigo Pérez Lorido (eds.), A Life in Language. Estudios en homenaje al profesor José Luis García Escribano, Oviedo, Universidad de Oviedo, pp. 301-335.

Martínez García, Hortensia (2007): "Estructura y cuantificación partitiva", Archivum, 57, pp. 169195.

Miguel, Elena de (2003): "Sobre la silepsis: un análisis léxico-semántico de la discordancia inducida por mitad", Revista de Investigación Lingüística, 1, 6, pp. 143-173.

NCE = Davies, Mark (2016-): Nuevo Corpus del Español: 2 billion words in web pages from 21 Spanish-speaking countries, <https://www.corpusdelespanol.org/web-dial/>. 
$N G L E=$ Real Academia Española y Asociación de Academias de la Lengua Española (20092011): Nueva gramática de la lengua española, Madrid, Espasa.

Pastor, Alberto (2016): "El adjetivo", en Javier Gutiérrez Rexach (ed.), Enciclopedia de lingüística hispánica, New York, Routledge, I, pp. 369-379.

Pérez-Jiménez, Isabel y Violeta Demonte (2017): "Agreement and interpretation of partitive constructions in Spanish: The dual nature of nominal features", Probus, 29, 2, pp. 355-395.

RAE, 1931 = Real Academia Española (1931): Gramática de la lengua española, Madrid, Espasa Calpe.

RAE, 1973 = Real Academia Española (1973): Esbozo de una nueva gramática de la lengua española, Madrid, Espasa Calpe.

Rodrigues, Erica dos Santos (2011): "Concordância verbal com construções partitivas - uma proposta de análise", Veredas, 15, 1, pp. 93-107.

Salvá, Vicente (1830): Gramática de la lengua castellana según ahora se habla, Madrid, Arco/ Libros, 1988.

San Julián Solana, Javier (2006): Sustantivos al servicio de la cuantificación: los cuantificativos intrínsecos, trabajo de investigación de doctorado, Oviedo, Universidad de Oviedo.

San Julián Solana, Javier (2007): "En torno a la distinción entre sustantivos colectivos y cuantificativos: los falsos cardinales", Acta Romanica Basiliensia, 19, pp. 37-52

San Julián Solana, Javier (2013): Los numerales sustantivos en español, Oviedo, Universidad de Oviedo.

San Julián Solana, Javier (2014): "La impronta del funcionalismo en los estudios lingüísticos del asturiano", Revista de Filoloxía Asturiana, 14, pp. 15-51.

San Julián Solana, Javier (2016a): La expresión sustantiva de la cuantificación en español, tesis doctoral, Oviedo, Universidad de Oviedo.

San Julián Solana, Javier (2016b): "El sustantivo cuantificador en la lingüística hispánica: revisión crítica y nueva propuesta", Círculo de Lingüística Aplicada a la Comunicación, 68, pp. 380-435, <http://dx.doi.org/10.5209/CLAC.54535>.

San Julián Solana, Javier (2018a): "La concordancia (ad sensum) con sustantivos cuantificadores en español", Verba, 45, pp. 67-106, <http://dx.doi.org/10.15304/verba.45.3816>.

San Julián Solana, Javier (2018b): "La heterogeneidad estructural de las pseudopartitivas en español", Círculo de Lingüística Aplicada a la Comunicación, 75, pp. 261-286, <https://doi.org/ 10.5209/CLAC.61357>.

San Julián Solana, Javier (2019): "La obtención de cuantificadores a partir de sustantivos designativos: adaptación contextual y creación léxica”, Revista Española de Lingüística, 49, en prensa.

Saussure, Ferdinand de (1986 [1916]): Curso de lingüística general, 24. ${ }^{a}$ ed., Buenos Aires, Losada.

Seco, Rafael (1968 [1930]): Manual de gramática española, 9. ${ }^{\mathrm{a}}$ ed., Madrid, Aguilar.

Seco, Manuel (1989 [1972]): Gramática esencial del español, 2.. ed., Madrid, Espasa Calpe.

Tucci, Emiliana (2016): La partitividad nominal, Berlin, Logos.

Vos, Riet (2002): "Las construcciones de cuantificador nominal en holandés y español", Foro Hispánico, 21, pp. 47-57.

Fecha de recepción: 23 de agosto de 2017

Fecha de aceptación: 6 de febrero de 2018 